Marit B. Henriksen

Sámi allaskuvla

Karen Inga Eira

Sámi allaskuvla

Jan Henry Keskitalo

Sámi allaskuvla

Kamil Øzerk

Universitetet i Oslo og Sámi allaskuvla

DOI: http://dx.doi.org/10.5617/adno.6293

\title{
Nasjonale prøver i lesing på samisk - på hvilke premisser?
}

\section{Sammendrag}

Tema for denne artikkelen er de nasjonale prøvene i lesing på samisk. Disse prøvene utformes på nord-, lule- og sørsamisk, og gjennomføres årlig for elever med samisk som førstespråk på 5., 8. og 9. klassetrinn. Problemstillingen omfatter bakgrunnen for utviklingen av et eget Rammeverk for nasjonale prøver $i$ lesing samisk, forhold omkring elevpopulasjonen, samt forhold knyttet til opplcerings- og lceremiddelsituasjonen; og hvordan disse faktorene påvirker utforming og oppfølging av prøvene. Presentasjonen av bakgrunnen for de nasjonale prøvene i lesing på samisk bygger på analyse av dokumentasjon fra prøveutviklingsprosjektet fra og med 2004 og fram til i dag. Videre identifiserer vi premissene for prøvene ut fra gjeldende lovverk og lcereplanverk. Undersøkelsen av elevpopulasjon og deltakelse bygger vi på analyse av tilgjengelig tallmateriale, kommentert statistikk og andre studier som tar for seg elevtall og opplæringssituasjonen for samiske elever. Vi legger her fram nye sammenstillinger av tallmaterialet, hvor vi ser på antall elever med samisk som opplceringsspråk i forhold til antall elever med samisk som førstespråk. I kapitlet om de nasjonale leseprøvene på samisk i møte med skolen tar vi for oss opplceringsog lceremiddelsituasjonen med bakgrunn i kommentert statistikk og forskningsrapporter, og vi ser at det er stor variasjon på dette området. Denne variasjonen problematiseres i forhold til elevenes muligheter til å oppøve gode leseferdigheter på samisk.

Nøkkelord: nasjonale prøver, lesing, samisk, nordsamisk, lulesamisk, sørsamisk, elevpopulasjon, prøveutvikling 


\title{
National reading tests in Sámi languages - on which terms?
}

\begin{abstract}
First language Sámi speaking students in Norway receive separate Sámimedium national literacy tests. Literacy tests are developed in North, Lule and South Sámi, and the tests are organized yearly for first language Sámi speaking students in grades 5, 8 and 9. In this article, we look at the background for the development of a separate Framework for national Sámi-medium literacy tests. We also examine conditions concerning the student population, and the situation regarding Sámi-medium instruction and Sámi-medium teaching materials; and how these factors affect the development and follow-up of the tests. The background for the national Sámi-medium literacy tests builds on an analysis of documentation produced in the period ranging from 2004, when the development of reading tests in Sámi started as a project, and up until today. We identify formal terms for the tests, determined by current legislation as well as national curricula. The examination of student population and test participation builds on available statistical material and on studies dealing with student numbers and Sámi-medium instruction in schools. We present new displays of material, where we compare numbers of students receiving Sámi-medium instruction with numbers of students registered as first language Sámi speakers. Based on studies and commented statistics, we examine the conditions for national reading tests compared to the daily situation in schools. The findings show that there is a high degree of variation concerning both organization of Sámi-medium instruction and available teaching materials, and we discuss how this affects students' opportunities to acquire satisfactory reading skills in Sámi.
\end{abstract}

Keywords: national tests, reading, Sámi language, North Sámi, Lule Sámi, South Sámi, student population, development of tests

\section{Nationála geahččaleamit sámegiela lohkamis - makkár eavttuid vuođul?}

\section{Čoahkkáigeassu}

Nationála geahččaleamit sámegiela lohkamis leat dán artihkkala fáddán. Geahččaleamit ráhkaduvvojit davvi-, julev- ja lullisámegillii, ja čađahuvvojit jahkásaččat 5., 8. ja 9. ceahki ohppiide geain lea sámegiella vuosttašgiellan. Artihkkalis lea golmmaoasat čuolbma: Mii guorahallat duogáža man dihte lei dárbu sierra njuolggadusaide sámegiela lohkama nationála geahččalemiid vaste (Rammeverk for nasjonale prøver i lesing samisk), áššiid mat gusket ohppiidpopulašuvdnii, ja vel áššiid mat gusket oahpahus- ja oahpponeavvodillái; ja mo buot dát áššit váikkuhit geahččalemiid 
ráhkadeapmái ja čuovvulahttimii. Nationála geahččalemiid duogáža čielggadeapmái leat atnán geahččalemiid ovdánahttinprošeavtta dokumentašuvnna mat leat čállon 2004 rájes gitta otnážii. Dasto leat meroštallan geahččalemiid eavttuid gustovaš lágaid ja oahppoplánaid vuođul. Ohppiidloguid ja oassálastima leat guorahallan almmolaš materiála vuođul, nu go čielggaduvvon statistihkka ja dutkamušat maid fáddán leat ohppiidlogut ja sámi ohppiid oahpahusdilli. Dán oasis ovdanbuktit ođđa vuogi bidjat oktii statistihkalaš loguid, das mii buohtastahttit man galli oahppis lea sámegiella oahpahusgiellan sin ektui geain lea sámegiella vuosttašgiellafágan. Viidáseappot mii guorahallat oahpahus- ja oahpponeavvodili čielggaduvvon statistihka ja dutkanraporttaid vuođul. Čájehuvvo ahte leat stuora variašuvnnat oahpahus- ja oahpponeavvodilis, ja mii árvvoštallat mo dát variašuvdna váikkuha ohppiid vejolašvuođaide hukset/háhkat buori lohkangelbbolašvuođa sámegillii.

Čoavddasánit: nationála geahččaleamit, lohkan, sámegiella, davvisámegiella, julevsámegiella, lullisámegiella, ohppiidpopulašuvdna, ohppiidlogut, geahččalemiid ráhkadeapmi

\section{Introduksjon}

Siden 2012 er det i Norge årlig gjennomført nasjonale prøver i lesing på samisk. Disse prøvene utvikles og gjennomføres på de tre samiske språkene som i Opplæringsloven er definert som opplæringsspråk, nemlig nordsamisk, sørsamisk og lulesamisk. De samiske leseprøvene utarbeides ut fra et eget Rammeverk for nasjonale prøver i lesing samisk; og på samme måte som i mange internasjonale testsystemer, måles ulike delkompetanser av lesekompetanse (Utdanningsdirektoratet, 2011, s. 5). Prøvene måler lesing på samisk som grunnleggende ferdighet $\mathrm{i}$ alle fag. De samiske leseprøvene gjennomføres parallelt med nasjonale prøver i lesing på norsk (bokmål og nynorsk), med de samme praktiske rammene for gjennomføring - prøvene gjennomføres digitalt (siden 2016), og prøvetiden er på 90 minutter.

De samiske leseprøvene er unike i verdenssammenheng. I Finland gjennomføres det ikke nasjonale prøver i noen fag eller ferdigheter (Opetushallitus Utbildningsstyrelsen, 2018). I Sverige gjennomføres nationella prov på ulike årstrinn for engelsk, matematikk og svensk / svensk som andrespråk, men ikke på noen samiske språk (Skolverket, 2018). Samiskspråklige elever tar altså prøvene på svensk. Vi kjenner til at det foreligger egne læreplaner og utvikles nasjonale prøver i literacy og numeracy blant annet på cymraeg (walisisk), på te reo Māori (maori) og på 'Ōlelo Hawai 'i (hawaiisk), som alle regnes som truede språk i ulik grad (UNESCO, 2018). Disse språkene er imidlertid i en helt annen samfunnsmessig situasjon enn de samiske språkene, på grunn av både antall 
talere og antall elever som følger undervisning og gjennomfører prøver (Hawaii State Department of Education, 2017; Rau, 2014; Welsh Government, 2018). Vi går derfor ikke nærmere inn på dette. Per i dag kjenner vi ikke til eksempler på gjennomføring av leseprøver på andre minoritets- eller urfolksspråk, hvor språkenes samfunnssituasjon er sammenlignbar med situasjonen for de samiske språkene.

Problemstillingen vår er tredelt:

1) Hvorfor har de nasjonale prøvene i lesing på samisk de rammene og den utformingsprosessen som de har i dag? Herunder ser vi også på hvilke premisser som ligger til grunn for utviklingen av rammeverket og for utformingen av prøvene.

2) Hvordan kan tallmateriale om elevpopulasjon og deltakelse sammenstilles for å kunne si noe om målgruppen for nasjonale prøver i lesing på samisk, og hvordan påvirkes prøveutformingen og kvalitetssikringen av prøvene av størrelsen på elevpopulasjonen?

3) Hva har opplærings- og læremiddelsituasjon og teksttilfang å si for gjennomføring og oppfølging av prøvene? Herunder ser vi på behov for oppfølging på skolenivå.

Omtalen av innføringen av de nasjonale prøvene i lesing på samisk bygger i hovedsak på gjennomgang og analyse av dokumentasjon som foreligger fra og med oppstarten av det første prosjektet i 2004, og fram til i dag. Materialet består først og fremst av faglige notater og prosjektrapporter, og er avgrenset til å gjelde dokumenter uten innsynsbegrensninger i henhold til Offentlighetsloven. Styrken i dette materialet ligger i at vi får tilgang til ulike trinn i arbeidsprosessen og til faglige vurderinger som ble gjort underveis. Materialets svakheter ligger $i$ at det er skrevet for et administrativt rapporteringsformål, og derfor ikke er utformet etter vitenskapelige standarder.

I prøveutviklingsdelen presenterer vi tall om elevpopulasjon og prøvedeltakelse. Denne presentasjonen er bygget på offentlig tilgjengelig statistikk og tidligere publiserte data. Selve sammenstillingen av materialet er ny, basert på behov identifisert under prøveutvikling og i forbindelse med arbeidet med denne artikkelen. Av personvernhensyn er det noen begrensninger i hvilke tall vi kan legge fram; dette påpeker vi spesielt der det er aktuelt. I prøveutviklingsdelen trekker vi inn og vektlegger prosjektgruppens egne erfaringer knyttet til arbeidet med prøvene.

I kapitlet om de nasjonale prøvene i lesing på samisk i møte med skolen baserer vi oss på tilgjengelig forskning og kommentert statistikk om opplæringsog læremiddelsituasjonen i samisk skole, samt prosjektgruppens erfaringer i forbindelse med prøveutviklingen. 


\section{Innføringen av nasjonale prøver i lesing på samisk}

\section{Bakgrunn}

Innføringen av nasjonale prøver i lesing på samisk henger tett sammen med historien og bakgrunnen for de øvrige nasjonale prøvene i Norge (Blömeke \& Olsen, 2018). Ett år etter oppstarten av de første norske prøvene, i mars 2004, fikk Prosjektgruppen for Nasjonale prøver på samisk (PNPS $\left.{ }^{1}\right)$ ved Sámi allaskuvla $^{2}$ i oppdrag fra Utdanningsdirektoratet å utvikle samiske nasjonale prøver. Utgangspunktet var at det skulle utvikles både lese- og skriveprøver på samisk (Todal, 2006, s. 405). Prosjektoppdraget fikk tittelen Nasjonale prøver i lesing og skriving på nord-, lule- og sørsamisk. Denne historikkdelen er i sin helhet bygget på statusrapporter fra prosjektgruppen (PNPS, 2004; PNPS, 2005; PNPS, 2006).

I og med at de samiske prøvene skulle utarbeides på disse tre opplæringsspråkene, ble det tilsatt nord-, lule- og sørsamiskspråklige medarbeidere, som hadde kontorsteder i de ulike språkområdene i Sápmi ${ }^{3}$. I september 2004 ble det besluttet å prioritere prøven i lesing på nordsamisk på 4. trinn. Samme høst ble de første prøvesettene utviklet og utprøvd på et lite utvalg elever. Leseprøver på nordsamisk og lulesamisk for 4 . trinn ble ferdigstilt og gjennomført som ordinære nasjonale prøver i 2005. Flere leseprøver ble utarbeidet og pilotert på de ulike språkene og for ulike trinn, men disse ble ikke ferdigstilt og gjennomført i og med at arbeidet med nasjonale prøver ble midlertidig stoppet i 2006.

Prosjektgruppen påpekte at det praktisk og tidsmessig var utfordrende at arbeidet med de samiskspråklige prøvene ble igangsatt ett år senere enn arbeidet med de nasjonale prøvene i lesing på norsk, men at man for nordsamisk og lulesamisk kunne dra nytte av erfaringer fra utprøvingen av leseprøvene på norsk, når det gjaldt både prøveutforming og vurderingsmåter (PNPS, 2004). Innenfor rammene av prosjektet ble det gjennomført utredninger om opplæring i nord-, lule- og sørsamisk, blant annet basert på intervjuer med lærere. Med bakgrunn i utredningene ble det vurdert om de sørsamiske prøvene burde være språkferdighetsprøver i stedet for prøver i elevenes grunnleggende lese- og skriveferdigheter, og om man burde se hen til vurderingssystemet i Det felles europeiske rammeverket for språk (Europakommisjonen, 2011; Council of Europe, 2001; PNPS, 2004; PNPS, 2005). Dette gikk man senere bort fra som en konsekvens av læreplanverket Kunnskapsløftet-Samisk (LK06S).

\footnotetext{
${ }^{1}$ På samisk Prošeaktajoavku Našunála geahččaleamit sámegillii.

${ }^{2}$ Høgskolens offisielle navn er fastsatt på samisk og engelsk: Sámi allaskuvla - Sámi University of Applied Sciences. Høgskolens engelske navn var tidligere Sámi University College. Ved oversettelse til norsk er det naturlig å bruke navneformen Samisk høgskole.

${ }^{3}$ Sápmi er betegnelsen på samenes bosetningsområde på nordsamisk (lulesamisk Sábme, og sørsamisk Saemie). Sápmi omfatter Nord-Norge, Trøndelag og noen områder så langt sør som Femundsmarka-traktene i Norge; Kolahalvøya i Russland, Lappland i Finland og Norrland i Sverige. Samene er en minoritet innenfor disse områdene. https://snl.no/S\%C3\%A1pmi
} 
I løpet av skoleåret 2006/07 ble det ikke utarbeidet og gjennomført nasjonale prøver. I denne perioden ble det utarbeidet et eget Rammeverk for nasjonale prøver for prøvene i lesing, regning og engelsk (Utdanningsdirektoratet, 2007). Rammeverket knyttet prøvene opp mot læreplanverket, fastsatte hva prøvene skal måle, hvordan de skal kvalitetssikres, samt tekniske kvalitetskrav for prøvene. De nasjonale prøvene i lesing på norsk, regning og engelsk ble gjeninnført fra og med 2007.

I juni 2007 fikk Utdanningsdirektoratet oppdraget med å legge til rette for nasjonale prøver i lesing på samisk. Fra oppdraget ble gitt tok det flere år før de samiske leseprøvene ble gjeninnført. En årsak til dette var at det tok tid å klarlegge premissgrunnlaget for de nasjonale prøvene i lesing på samisk og utvikle rammeverket for disse prøvene. Rammeverk for nasjonale prøver (Utdanningsdirektoratet, 2007) tok ikke høyde for faktorer som er særegne for opplæringen i de samiske språkene og for språkenes samfunnssituasjon. Utdanningsdirektoratet var i dialog med Sametinget, Sámi allaskuvla ved Sámi lohkanguovddás ${ }^{4}$ og Fylkesmannen i Finnmark for å komme fram til rammebetingelser for nasjonale prøver i lesing på samisk. Sentralt i denne prosessen var blant annet Opplæringslovens bestemmelser om retten til opplæring i og på samisk, og læreplanverkets muligheter for valg av opplæringsnivå i samisk språk. Det ble videre diskutert om de nasjonale prøvene i samisk skulle være oversettelser av de norske prøvene, eller om det skulle utvikles egne prøver. Problemstillingene her var knyttet til prøveutforming for små elevpopulasjoner, herunder validitet, reliabilitet og pilotering, samt utfordringer knyttet til offentliggjøring av prøveresultater.

Prosessen med å klarlegge premisser og rammebetingelser for samiske nasjonale prøver pågikk over flere år, og resulterte $\mathrm{i}$ et eget Rammeverk for nasjonale prøver i lesing samisk, som ble fastsatt i september 2011 (Utdanningsdirektoratet, 2011). Sámi lohkanguovddáš ved Sámi allaskuvla fikk oppdraget med utvikling av nasjonale prøver i lesing på samisk i oktober 2011, og de første prøvene på nordsamisk ble avholdt høsten 2012. Fra og med 2013 har det også vært prøver på lule- og sørsamisk. Prøvene har deretter blitt gjennomført årlig.

\section{Språklige forhold}

Samiske språk tilhører den finsk-ugriske språkgruppen, og det samiske språkområdet strekker seg tradisjonelt over deler av Norge, Sverige, Finland og Russland. I Norge tales nordsamisk tradisjonelt i Finnmark, Troms og deler av nordre Nordland. Lulesamisk tales tradisjonelt i Saltenområdet i Nordland, og Tysfjord er kjerneområdet for lulesamisk. Sørsamisk tales tradisjonelt fra Rana i Nordland og så langt sørover som til Elgå i Engerdal kommune i Hedmark. Disse språkene tales også i våre naboland - nordsamisk tales både i Norge, Sverige og Finland, og lulesamisk og sørsamisk tales både i Norge og

\footnotetext{
${ }^{4}$ Sámi lohkanguovddáš - Sáme låhkåmguovdásj - Saemien lohkemejarnge - Senter for samisk i opplæringa, f.o.m. 1.1.2018 Nasjonalt senter for samisk i opplæringa.
} 
Sverige. Dette henger sammen med at de samiske dialektgrensene går i retningen øst-vest, mens de skandinaviske statsgrensene er trukket i retningen nord-sør, tvers gjennom de tradisjonelle samiske språkområdene ${ }^{5}$ (Todal, 2006, s. 405-406.) Disse tre samiske språkene har hver sine standardiserte skriftformer og hver sin unike samfunnssituasjon. På det interaktive nettstedet UNESCO Atlas of the World's Languages in Danger, som ofte kalles «UNESCOs rødliste», er nordsamisk klassifisert som et truet språk, og sørsamisk og lulesamisk klassifiseres som alvorlig truede språk (UNESCO, 2018). I Norge har vi dessuten språkene østsamisk og pitesamisk, som ikke omfattes av Opplæringslovens bestemmelser. ${ }^{6}$

Nordsamisk og lulesamisk er nabospråk, og talere av disse språkene kan stort sett forstå hverandre, til tross for ulikheter i fonologi, morfologi, syntaks og ordforråd. Sørsamisk er ikke nabospråk til verken lulesamisk eller nordsamisk, og betydelige språkforskjeller vanskeliggjør gjensidig forståelse mellom nord-, lule- og sørsamisktalende. De samiske språkenes morfologiske og syntaktiske struktur skiller seg betydelig fra norsk og andre språk som tilhører den indoeuropeiske språkfamilien. Utfyllende informasjon om samisk morfologi og syntaks er tilgjengelig gjennom litteratur på blant annet norsk, svensk og engelsk, se for eksempel Nordsamisk grammatikk (Nickel \& Sammallahti, 2011), Lulesamisk grammatik (Spiik, 1989), Sydsamisk grammatikk (Bergsland, 1994) og The Saami Languages - An Introduction (Sammallahti, 1998).

\section{Premisser for nasjonale prøver i lesing på samisk}

De overordnede premissene for nasjonale prøver i lesing på samisk følger av bestemmelsene i Sameloven, i Opplæringslovens kapittel 6 Samisk opplcering, i læreplanverket LK06S, og i Rammeverk for nasjonale prøver i lesing samisk fra 2011.

Samelovens $\S 1-5$ slår fast at samisk og norsk er likeverdige språk. Samelovens $\S 3$ omhandler bruken av samisk språk i det offentlige, og fastsetter at samisk og norsk skal være likestilte språk innenfor forvaltningsområdet for samisk språk ${ }^{7}$, samt på en del andre områder (bl.a. innen opplæring, helse- og sosialsektoren og innenfor kriminalomsorg og rettsvesen) (Kommunal- og moderniseringsdepartementet, 2008). Opplæringsloven fastslår samiske elevers

\footnotetext{
${ }^{5}$ Oversiktskart og annen informasjon om samiske språk finnes på ulike nettsteder. Se for eksempel Sámi giellalávdegoddi/Samisk språknemnd (SGL) http://www.giella.no/artikkel.aspx?MId1=3381\&AId=56 (Sámediggi - Sametinget, 2010) og Store norske leksikon (SNL) https://snl.no/samisk.

${ }^{6}$ Språkene østsamisk og pitesamisk klassifiseres som henholdsvis alvorlig truet og kritisk truet på UNESCOs rødliste (UNESCO, 2018).

${ }^{7}$ I forvaltningsområdet for samisk språk inngår kommunene Guovdageaidnu/Kautokeino, Kárášjohka/Karasjok, Deatnu/Tana, Unjárga/Nesseby og Porsángu/Porsanger i Finnmark; Gáivuotna/Kåfjord og Loabák/Lavangen i Troms; Divtasvuodna/Tysfjord og Aarborte/Hattfjelldal i Nordland; Snåase/Snåsa, Raarvihke/Røyrvik og Røros i Trøndelag. I tillegg omfattes de fire nordligste fylkeskommunene (Finnmark, Troms, Nordland og Trøndelag) av forvaltningsområdet. (Sámediggi - Sametinget, 2018)
} 
individuelle rett til opplæring i samisk ${ }^{8}$, uavhengig av hvor i landet de bor. Denne retten gjelder for nordsamisk, lulesamisk og sørsamisk. I samiske distrikt har alle elever rett til opplæring i og på samisk. Utenfor samiske distrikt gjelder denne retten dersom visse vilkår er oppfylt. (Kunnskapsdepartementet, 2018)

Læreplanverket LK06S gir elevene mulighet til å velge mellom flere ulike alternativer for opplæring i samisk. Læreplanen i samisk som førstespråk er beregnet for elever som har samisk som hjemmespråk, og som snakker samisk når de begynner på skolen. Disse elevene får den første lese- og skriveopplæringen på samisk - og de får opplæring i norsk i henhold til læreplan i norsk for elever med samisk som førstespråk. Elevene kan også velge å ha opplæring i to førstespråk, både samisk og norsk ${ }^{9}$. De kan også velge å ha samisk som andrespråk eller som fremmedspråk (Sámediggi - Sametinget, 2017).

Rammeverket som ble fastsatt i 2011, fastsetter at de nasjonale prøvene i lesing på samisk skal gjennomføres av elever som har samisk som førstespråk, og at prøvene holdes i høstsemesteret på 5., 8. og 9. trinn. De nasjonale prøvene i lesing på samisk skal i likhet med leseprøvene på norsk kartlegge i hvilken grad elevenes ferdigheter er i samsvar med kompetansemålene i læreplanverket LK06S (Utdanningsdirektoratet, 2011). En rent praktisk følge av at elevene har en individuell rett til opplæring i og på samisk er at det kan være stor variasjon i tilrettelegging av undervisningen og i klasse- eller gruppestørrelse. Dette går vi nærmere inn på nedenfor.

Koblingen av nasjonale prøver i lesing på samisk opp mot LK06S innebærer en forutsetning om at de samiske prøvene må utvikles på eget grunnlag som egne prøver. I henhold til rammeverket skal tekstutvalget i prøvene først og fremst bestå av tekster skrevet originalt på samisk og baseres på det tekstmangfoldet som elevene vanligvis møter (Utdanningsdirektoratet, 2011). I dette ligger det at de samiske leseprøvene ikke kan være rene oversettelser av de norske leseprøvene, i og med at de norske leseprøvene er utviklet med utgangspunkt i både et annet læreplanverk og et annet tekstutvalg (Todal, 2006, s. 407-410; Sámi lohkanguovddáš, 2008).

Rammeverket forutsetter at prøvene utformes i tråd med vanlige standarder for prøvekonstruksjon, og de skal vurderes i henhold til vanlige psykometriske krav til reliabilitet og validitet. Prøvenes reliabilitet uttrykkes med en alphakoeffisient, og det forutsettes at prøvene har en alpha-koeffisient på 0,85. Videre fastsetter rammeverket at de nasjonale prøvene i lesing på samisk ikke skal

\footnotetext{
${ }^{8}$ Lovens § 6-1 definerer hvem som omfattes av bestemmelsene, hva som regnes som samiske distrikt, og hvilke språk som omfattes av bestemmelsene (nordsamisk, lulesamisk og sørsamisk). Av § 6-2 framgår følgende: «I samiske distrikt har alle i grunnskolealder rett til opplæring i og på samisk. Utanfor samiske distrikt har minst ti elevar i ein kommune som ønskjer opplæring i og på samisk, rett til slik opplæring så lenge det er minst seks elevar igjen i gruppa. [...] Utanfor samiske distrikt har samar i grunnskolealder rett til opplæring i samisk. Departementet kan gi forskrifter om alternative former for slik opplæring når opplæringa ikkje kan givast med eigna undervisningspersonale på skolen.» (Kunnskapsdepartementet, 2018) Les mer i Opplæringslovens kapittel 6 Samisk opplæring.

${ }^{9}$ For fullstendige opplysninger om alternativene for opplæring i samisk, se Læreplaner i samisk - flere alternativer (Sámediggi - Sametinget, 2017).
} 
piloteres. Dette grunngis med at den totale elevmassen er for liten, og at en eventuell pilotering innebærer en risiko for at prøven kan bli allment kjent (Utdanningsdirektoratet, 2011). Rammeverket stiller krav til kvalitetssikring av prøvenes validitet. Dette gjelder både i hvilken grad prøvene måler de ferdighetene som det er ønskelig at de skal måle, vurdering av prøvenes innhold og prøvenes sammenheng med læreplanverket LK06S (Utdanningsdirektoratet, 2011).

\section{Prøveutvikling og kvalitetssikring av prøvene}

\section{Elevpopulasjon og deltakelse}

Antallet elever i målgruppen for nasjonale prøver i lesing på samisk har vært et gjennomgående tema både i arbeidet med utvikling av rammeverk og senere ved statistisk analyse av elevresultater. I GSI - Grunnskolenes informasjonssystem (Utdanningsdirektoratet GSI, 2018) - er samlet antall elever med samisk som opplæringsspråk på landsbasis offentliggjort fra og med skoleåret 1998/99 ${ }^{10}$. Antall elever på både fylkesnivå, kommunenivå og skolenivå er unntatt offentlighet. Det går heller ikke fram hvor mange av elevene som har henholdsvis nord-, lule- eller sørsamisk som opplæringsspråk på hvert av trinnene. Det samlede antallet elever i hele landet med samisk som fag er offentliggjort i GSI fra og med skoleåret 2001/02. Tallene viser antall elever per årstrinn som har faget samisk enten som førstespråk, andrespråk (to alternativer) eller fremmedspråk fordelt på nord-, lule- eller sørsamisk. Også her oppgis kun samlet antall elever i hele landet.

Det er svært vanskelig å anslå hvor mange elever på hvert av årstrinnene 110 som får samiskopplæring via fjernundervisning, da tilgjengelig statistikk bare viser det totale antall elever i hele grunnskolen som får samiskopplæring på denne måten (Johansen, 2015). I andre artikler som presenterer data om elevtall i samiskopplæringen brukes tall for hele den samiske elevpopulasjonen fra 1. til 10. årstrinn uten å gå inn på tallene for det enkelte årstrinn (f.eks. Todal, 2006, s. 406-407; Todal, 2010, s. 158; Todal, 2012, s. 109; Todal, 2013, s. 33; Johansen, 2015; Rasmussen, 2015, s. 19).

I de følgende diagrammene (figur 1-3) viser vi data for antall elever per årstrinn som er registrert med samisk som opplæringsspråk, antall elever registrert med opplæring i samisk som førstespråk, og antall registrerte elevresultater ved nasjonale prøver i lesing på samisk. Vi har her hentet inn data fra hvert av skoleårene i GSI og sammenstilt data for 5., for 8. og for 9. trinn i nye tabeller.

\footnotetext{
${ }^{10}$ Det er uklart for oss hvorfor disse tallene ikke har vært offentliggjort før 1998/99, da vi med sikkerhet vet at det har vært elever med samisk som opplæringsspråk og elever med samisk som førstespråk også før dette (Todal, 2006, s. 411).
} 
I tabellen og diagrammet i figur 1 viser de oransje stolpene det samlede antall elever på 5. trinn som i skoleårene fra 2001/02 til 2017/18 har hatt samisk som førstespråk, og blå stolper antall registrerte resultater fra nasjonale prøver i lesing på samisk i perioden 2012-2017. Linjen viser samlet antall elever på 5. trinn som har hatt ett av de samiske språkene som opplæringsspråk.

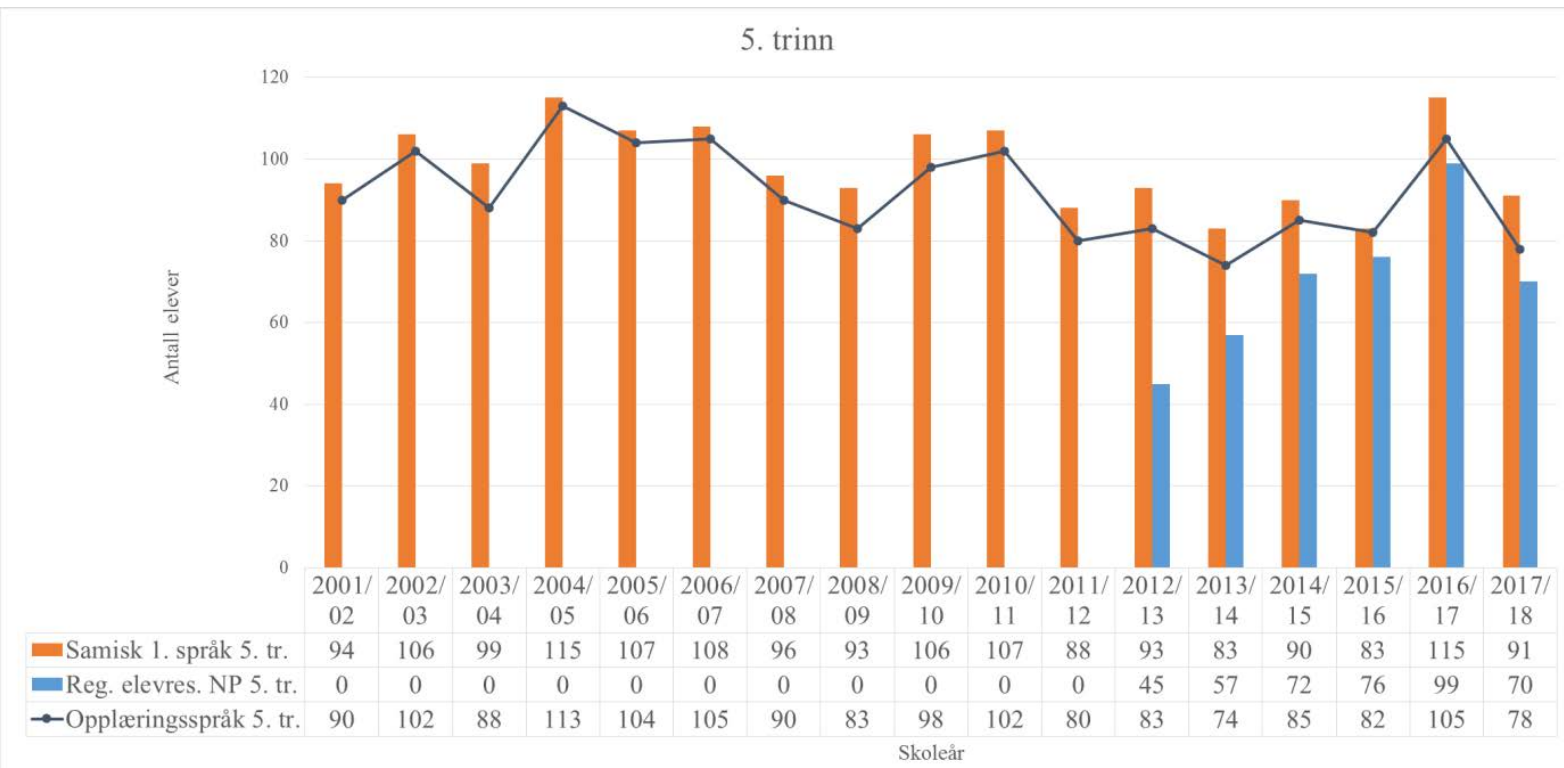

Figur 1. Antall elever per år på 5. trinn som har hatt opplæring i ett av de samiske språkene som førstespråk, antall som har tatt nasjonale samiske leseprøver, og antall som har hatt ett av de samiske språkene som opplæringsspråk.

GSI-tallene viser at antall elever på 5. trinn med lulesamisk eller sørsamisk som førstespråk i skoleårene fra 2012/13 til 2017/18 har variert mellom 0 og 7 elever med lulesamisk, og mellom 1 og 7 elever med sørsamisk (Utdanningsdirektoratet GSI, 2018). Dette gjenspeiles også i antall registrerte prøveresultater. Antall elevresultater fra gjennomføring av nasjonale prøver i lesing på sørsamisk og lulesamisk er så lavt at disse ikke skilles ut som egne kategorier, blant annet av personvernhensyn. Prosentandelen elever som har gjennomført nasjonale prøver på nordsamisk i perioden 2012-2017 har årlig utgjort mellom 87 \% og $100 \%$ av det samlede antallet elevresultater.

Figur 2 viser tilsvarende informasjon for elever på 8. trinn. GSI-tallene viser at i skoleårene fra 2012/13 til 2017/18 har antall elever på 8. trinn med lulesamisk som førstespråk variert mellom 0 og 4 elever per år, og antall elever med sørsamisk har variert mellom 1 og 3 elever per år (Utdanningsdirektoratet GSI, 2018). Dette gjenspeiles også i antallet registrerte prøveresultater. For 8. trinn har andelen elever som tar de nordsamiske prøvene i perioden 2012-2017 vært mellom $92 \%$ og $100 \%$ av samlet antall registrerte elevresultater. Også her er antall registrerte resultater så lavt for lulesamisk og sørsamisk at disse ikke skilles ut som egne kategorier. 


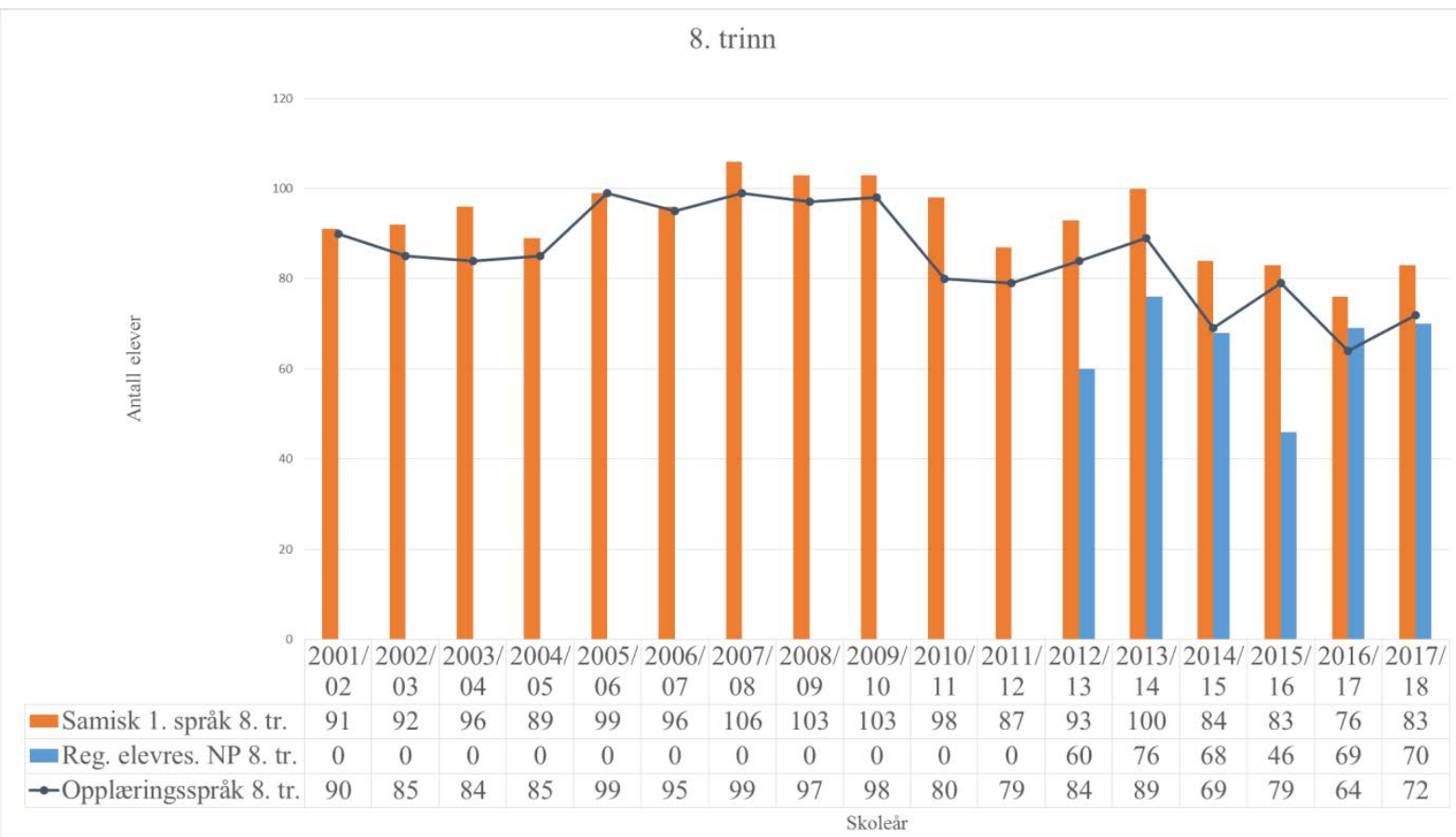

Figur 2. Antall elever per år på 8. trinn som har hatt opplæring i ett av de samiske språkene som førstespråk, antall som har tatt nasjonale samiske leseprøver, og antall som har hatt ett av de samiske språkene som opplæringsspråk.

Figur 3 viser tilsvarende informasjon for elever på 9. trinn.

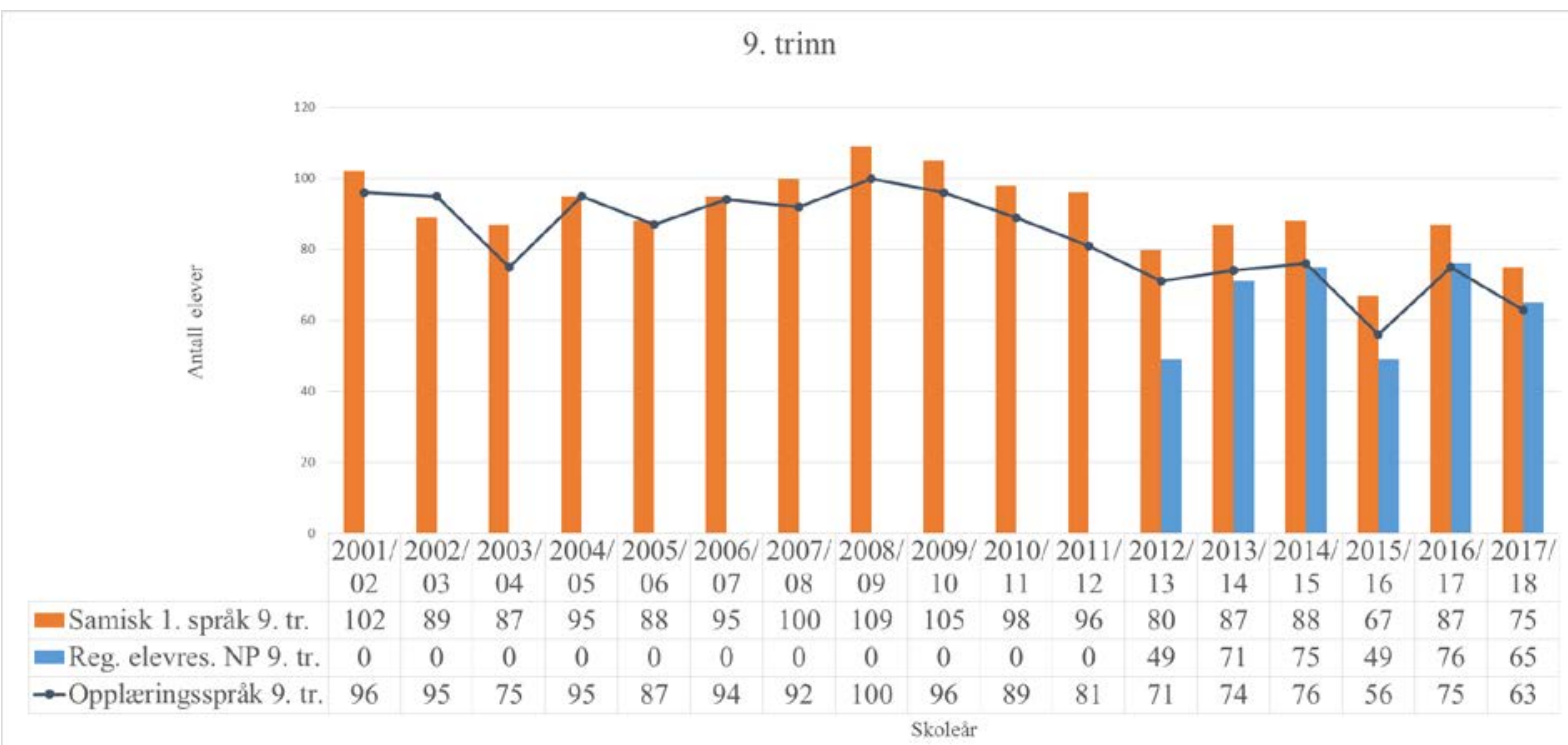

Figur 3. Antall elever per år på 9. trinn som har hatt opplæring i ett av de samiske språkene som førstespråk, antall som har tatt nasjonale samiske leseprøver, og antall som har hatt ett av de samiske språkene som opplæringsspråk.

GSI-tallene viser at i skoleårene fra 2012/13 til 2017/18 har antall elever på 9. trinn med lulesamisk som førstespråk variert mellom 0 og 3 elever per år, og antall elever med sørsamisk har variert mellom 0 og 2 elever per år (Utdanningsdirektoratet GSI, 2018). Dette gjenspeiles også i antall registrerte prøveresultater. For 9. trinn har andelen elever som tar de nordsamiske prøvene i perioden 
2012-2017 vært mellom 93 \% og $100 \%$ av samlet antall registrerte elevresultater. Også her er antall registrerte resultater så lavt for lulesamisk og sørsamisk at disse ikke skilles ut som egne kategorier.

GSI-tallene viser at antallet elever med samisk som førstespråk på 5., på 8. og på 9. trinn i perioden 2001-2017 har variert mellom 67 og 115 elever per trinn per år. Av antall elever på 5. trinn med faget samisk som førstespråk, har gjennomsnittlig 93 \% av dem også hatt samisk som opplæringsspråk i perioden fra 2001/02 til 2017/18. Tilsvarende tall for 8. trinn er $92 \%$, og for 9. trinn 91 $\%{ }^{11}$ Det er altså en forholdsvis liten andel elever som har samisk som førstespråk kun som fag. Det er ikke mulig å si hvor disse elevene befinner seg geografisk, hvilket av de tre samiske språkene de får opplæring i, eller om de får opplæringen stedbasert eller via fjernundervisning (Eira, 2018).

Begrepet opplæringsspråk er ikke nærmere definert i lov eller regelverk. I GSI skal elevene registreres etter hvilken målform elevene/foresatte velger i alle andre fag enn norsk (Utdanningsdirektoratet GSI, 2018). Det er imidlertid grunn til å problematisere begrepet, da det ikke finnes tilgjengelige statistikker som viser om alle elevene som er oppgitt med samisk som opplæringsspråk, virkelig får opplæringa på samisk i alle fag (unntatt norskfaget), og med læremidler på samisk. Dette ble problematisert av Todal under den første prøveutviklingsperioden (Todal, 2006, s. 408-409).

\section{Kvalitetssikring i prøveutformingen}

Prøvetekstene består av skjønnlitterære tekster og faglitterære tekster i ulike sjangre og av variert format, både sammenhengende (kontinuerlige) tekster, diskontinuerlige tekster og sammensatte/multimodale tekster. Tekstene har omhandlet temaer fra elevenes skolefag (samfunnsfag, naturfag, samisk, musikk og

\footnotetext{
${ }^{11}$ Gjennomsnittlig prosentandel av elevene som har samisk både som opplæringsspråk og som førstespråk fra skoleår 2001/02 til 2017/18 fordeler seg slik:

5. trinn: I perioden fra 2001/02 til 2017/18 har gjennomsnittlig $93 \%$ av elevene som har hatt faget samisk som førstespråk, også hatt samisk som opplæringsspråk (median = 94 \%; maks. = 99 \% (2015/16); min. = 86 \% (2017/18)).

I perioden fra 2012/13 til 2017/18 har gjennomsnittlig $91 \%$ av elevene som har hatt faget samisk som førstespråk, også hatt samisk som opplæringsspråk (median = 90 \%; maks. = 99 \% (2015/16); min. = 86 \% (2017/18)).

8. trinn: I perioden fra 2001/02 til 2017/18 har gjennomsnittlig $92 \%$ av elevene som har hatt faget samisk som førstespråk, også hatt samisk som opplæringsspråk (median = 92 \%; maks. = 100 \% (2005/06), min. = 82 \% (2014/15)).

I perioden fra 2012/13 til 2017/18 har gjennomsnittlig $88 \%$ av elevene som har hatt faget samisk som førstespråk, også hatt samisk som opplæringsspråk (median = 88 \%; maks. = 95 \% (2015/16); min. = 82 \% $(2014 / 15))$.

9. trinn: I perioden fra 2001/02 til 2017/18 har gjennomsnittlig $91 \%$ av elevene som har hatt faget samisk som førstespråk, også hatt samisk som opplæringsspråk (median = 91 \%; maks. = 107 \% (2002/03); min. = 84 \% (2011/12, 2015/16 og 2017/18)).

I perioden fra 2012/13 til 2017/18 har gjennomsnittlig $86 \%$ av elevene som har hatt faget samisk som førstespråk, også hatt samisk som opplæringsspråk (median = 86 \%; maks. = 89 \% (2012/13); min. = 84 \% (2015/16 og 2017/18)).

Merk at prosenter over 100 er mulig, siden enkelte elever med faget samisk som andrespråk kan ha hatt samisk som opplæringsspråk.
} 
duodji ${ }^{12}$ ) og aktuelle kultur- og samfunnsrelaterte temaer fra det samiske samfunnet og samiske media. De fleste oppgavene er flervalgsoppgaver, men det blir også gitt en del åpne oppgaver.

Pilotering er en vanlig metode for å kvalitetssikre prøvene med tanke på validitet og reliabilitet. Det lave antallet elever i målgruppen for de nasjonale prøvene i lesing på samisk fører imidlertid til at det er vanskelig å gjøre statistisk holdbare piloteringer uten at man involverer så og si hele elevpopulasjonen i piloteringen. For lule- og sørsamisk sin del vil pilotering være umulig. Det ville være mulig å pilotere de nordsamiske leseprøvene i de største elevgruppene som man finner i det nordsamiske kjerneområdet. Konsekvensen av dette ville da bli at de samme skolene «velges» som piloteringskoler hvert år. Disse skolene vil da med stor sannsynlighet kjenne innholdet i kommende prøver. Dessuten ville dette medføre at de samme skolene må forholde seg til flere prøver og piloteringer årlig, noe som ville bli en ekstrabelastning på enkeltskoler og enkeltklasser som man bør unngå (Todal, 2006, s. 410-411). I teorien kunne man gjennomført pilotering i samiskklasser i Sverige eller Finland. Dette har vi valgt å ikke gjøre i og med at læreplanene i samiskfagene er ganske forskjellige i Norge, Sverige og Finland. Hvis man skulle gå inn på en slik løsning, krever det at man gjør omfattende analyser og sammenligninger av de ulike læreplanverkene.

I og med at de samiske leseprøvene ikke piloteres, fordres det andre måter å kvalitetssikre prøvene på. Prøveutviklerne velger helst autentiske tekster hvor originalen finnes på (minst) ett av de samiske språkene, men bruker iblant tekster hvor originalen er skrevet på norsk, for så å tilpasse disse. Tekst og tema vurderes opp mot læreplanmålene og hvilke læremidler som finnes om emnet på hvert av de samiske språkene. Prøveutviklingsprosessen omfatter alltid oversetting av tekstene de samiske språkene imellom, i og med at tekstutvalget på de tre språkene ikke er ekvivalent. Kultur, levesett og råstofftilgang er forskjellig for de tre språkområdene; dette innebærer at begrepsapparat og terminologi heller ikke er ekvivalent på de tre språkene. For eksempel kan en forvente langt større kjennskap til laksefiske og fiskerelatert terminologi hos elever fra nord- og lulesamisk område enn hos elever fra sørsamisk område. Tilsvarende kan man forvente større kjennskap til reindriftsrelaterte emner og terminologi hos elever fra nordsamisk område (indre Finnmark) og fra sørsamisk område, enn hos elever fra lulesamiske eller sjøsamiske områder.

Også når vi vurderer tekster som omhandler nyere fagområder, undersøker vi først om det finnes etablert terminologi om fagområdet på alle de tre samiske språkene, og i hvor stor grad terminologien er i bruk i samiske læremidler eller andre tekster for elever. Vi begynner med å oversette teksten mellom de tre språkene. Dersom det under oversettelsesarbeidet viser seg nødvendig å utvikle ny terminologi på ett av språkene, fører dette til at tekstene får ulikt nivå med

\footnotetext{
${ }^{12}$ Samisk håndverk og kunsthåndverk.
} 
hensyn til vanskegrad og kompleksitet. Dette vil gi større utfordringer for elever som leser dette språket, i og med at de ikke kjenner terminologien fra tidligere. I slike tilfeller blir teksten vanligvis vraket. Iblant har vi likevel vurdert et tema som så aktuelt at vi på bakgrunn av ulike kilder har utarbeidet egne prøvetekster om emnet.

Alle tekstene må bearbeides i flere omganger for å få et presist innhold uten å bruke terminologi og språk som er svært ukjent for elevene. Vår arbeidsprosess har mye til felles med prosessen for oversettelse og tilpasning av testinstrumenter slik den beskrives hos WHO, og omfatter oversettelse fra kildespråk til målspråk (forward translation), oversettelse fra målspråket tilbake til kildespråket (back translation); prøveutviklerne arbeider seg gjennom tekst og spørsmål (pre-testing) og deretter utarbeidelse av en endelig versjon. (World Health Organization, 2018.) Dette vil i vårt tilfelle som oftest innebære at også den opprinnelige kildespråksteksten er endret. Formålet med denne prosessen er å sikre at prøvetekst og oppgaver er språklig, begrepsmessig og kulturelt likeverdige. Dette har stor betydning for om teksten vil være likeverdig i vanskegrad og kompleksitet på alle de tre samiske språkene.

\section{De nasjonale leseprøvene på samisk i møte med skolen}

\section{Forhold som påvirker leseferdigheter på samisk}

Rammeverket forutsetter at prøvene skal baseres på det tekstmangfoldet som elevene møter, fortrinnsvis autentiske tekster skrevet originalt på samisk (Utdanningsdirektoratet, 2011). Prøveutviklingen påvirkes dermed av det totale teksttilfanget innen forskjellige fag og temaer på de tre samiske språkene. Sammenlignet med norsk finnes det ikke store mengder papirbaserte eller digitale tekster på noen av de tre samiske språkene. Det største teksttilfanget om ulike temaer finnes på nordsamisk. Teksttilfanget på lulesamisk og sørsamisk er langt mindre enn på nordsamisk, når det gjelder både læremidler og andre teksttyper. Det finnes ikke læremidler innen alle fag og emner som inngår i læreplanverket, verken for nord-, lule- eller sørsamisk. Læremiddelsituasjonen er alvorligst for lule- og sørsamisk (Rasmussen, 2015, s. 29-32; Solstad et al., 2010, s. 102). Dette innebærer at elevene får ulik erfaring med samisk fagspråk innen ulike skolefag og temaer.

Samiske elever tilbys i ulik grad opplæring på samisk i andre fag enn samisk som språkfag (Solstad et al., 2010, s. 31, 102-104). På den ene siden finner vi skolene i kommunene Kautokeino og Karasjok i Finnmark, hvor majoriteten av skolenes elever har nordsamisk som førstespråk og hjemmespråk, skolene har samisk som opplæringsspråk i så å si alle fag, og elevgruppene er forholdsvis store. På den andre siden finner vi skoler hvor enkeltelever får opplæring kun i samisk som fag, og da hovedsakelig gjennom fjernundervisning. Derimellom finnes kommuner hvor elevene får opplæring i og på nord-, lule- eller sørsamisk 
ved enkelte (mindre) skoler, eller i egne klasser. Denne variasjonen i opplæringssituasjonen for førstespråkselevene innebærer at det er betydelig variasjon når det gjelder i hvor stor grad elevene opplever å være i en samiskspråklig setting i sin skolehverdag og sine øvrige daglige omgivelser. Dette er også med på å gi stor variasjon i elevenes ordforråd på samisk innen skolefagenes temaer, og å føre til ulik leseforståelse. Kjølaas problematiserer i sin undersøkelse (Kjølaas, 2005) situasjonen for tospråklige elevers skolespråk. Elevene i undersøkelsen er bosatt utenfor det samiske kjerneområdet, hvor situasjonen er slik at majoritetsspråket dominerer på de fleste samfunnsområder. Undersøkelsen viser at elevene i større grad tilegner seg ordforråd om ulike temaer på majoritetsspråket norsk enn på minoritetsspråket samisk, på grunn av majoritetsspråket dominans; og at dette har innvirkning på elevenes leseforståelse på både minoritets- og majoritetsspråket (Kjølaas, 2005, s. 24).

De samiske skoleforskerne Keskitalo og Linkola har, på grunnlag av undersøkelser av skolenes lingvistiske landskap, påpekt viktigheten av språkets synlighet, status og tilgjengelighet, spesielt i skolesammenheng, men også på ulike samfunnsområder når det gjelder å bygge opp under elevenes læring og lesing i og på samisk (Linkola \& Keskitalo, 2015). Outakoski har i sin forskning om konteksten for samiske elevers literacy pekt på noe av det samme (Outakoski, 2015). Dette er en aktuell problemstilling ved alle skoler i de samiske områdene, i og med de samiske språkenes stilling som minoritetsspråk. Problemstillingen er dessuten særlig aktuell for situasjonen til de samiske elevene som vokser opp utenfor samiske kjerneområder og som har et svært begrenset «samiskspråklig landskap» som bygger opp under deres læring og lesing på samisk (Nordlandsforskning, 2010, s. 107).

Samlet sett påvirker dette samiske elevers muligheter til å oppøve lesing i samisk som grunnleggende ferdighet $\mathrm{i}$ alle fag. Vi ser at arbeidet med de nasjonale samiske leseprøvene medvirker til å sette samisk språk på dagsorden, og regner med at dette på sikt kan bidra til å høyne statusen for samisk som språkfag og opplæringsspråk, og dermed bidra til økt fokus på læremiddelsituasjonen.

\section{Oppfølging av prøvene i skolen}

Et overordnet formål med de nasjonale prøvene i lesing er å gi skolene kunnskap om elevenes grunnleggende ferdigheter i lesing. Det forventes at informasjonen fra nasjonale prøver i lesing skal danne grunnlag for underveisvurdering og kvalitetsutvikling i hver enkelt skole og kommune, og følgelig i skolesystemet som helhet. Et annet sentralt formål med prøvene er at lærerne skal kunne bruke elevresultatene i oppfølgingen av sine elever og i sammenheng med underveisvurdering og tilpasset opplæring.

Det samiske språksamfunnet er lite, men geografisk er samisktalende spredt over et stort område. Det er store avstander mellom skoler som tilbyr undervisning i samisk som førstespråk, og mellom lærere som underviser i samisk som 
førstespråk. Lærerne har derfor etterspurt kompetanseutvikling og arenaer for erfaringsutveksling (Solstad et al., 2010; Sámi lohkanguovddáš, 2011, s. 26).

Det lave antallet elevresultater fører til at man ikke kan publisere statistiske resultatdata på samme måte som for de norske leseprøvene. Blant annet blir beregningen av mestringsnivå for ustabilt til å kunne publiseres. Det er derfor behov for andre måter å følge opp resultatene på. For å imøtekomme dette samt lærernes ønske om kompetanseutvikling, har Sámi Lohkanguovddáš satset på en kollektiv strategi som omfatter følgende elementer:

a. Besøke skoler og arrangere samlinger for samiske lærere, og presentere analyser av prøveresultatene for dem

b. Drøfte resultatene med lærerne og utveksle synspunkter og erfaringer

c. Utvikle pedagogisk-metodiske ideer og tiltak for tilpasset opplæring

d. Forbedre de nasjonale prøvenes utforming og innhold i lys av tilbakemeldinger fra lærere og skoler

Det har vært arrangert en rekke regionvise lærersamlinger med fokus på ulike aspekter av leseopplæring og språkopplæring, også sett i lys av tospråklighet. På samlingene har vi lagt vekt på utvikling av lesing som grunnleggende ferdighet $\mathrm{i}$ alle fag. Med utgangspunkt i prøveresultatene har også elevenes styrker og svakheter ved lesing av ulike tekster vært et sentralt tema.

Det er flere grunner til at vi planlegger å videreføre arbeidet med kollektiv erfaringsutveksling og kompetanseutvikling. Vi opplever at det blant samiske lærere er en økt bevissthet om de nasjonale prøvene. Lærerne ser ut til å bli mer bevisste på mulighetene for å bruke prøveresultatene som redskap for utviklingsarbeid i opplæringa. Det vil også være mulig å dra nytte av funn fra prøveresultater i produksjonen av læremidler og læringsressurser. Vi ønsker også at resultatene fra prøvene i enda større grad skal ha en støttende funksjon. Dette er spesielt viktig fordi mange samisklærere opplever å være svært alene i sin undervisningssituasjon - nærmeste kollega kan være på en annen skole, i en annen kommune eller kanskje i et annet fylke. Det er derfor viktig at apparatet rundt de nasjonale prøvene i lesing på samisk har en innretning som i størst mulig grad støtter samiske lærere i deres daglige virke.

\section{Konklusjon}

De nasjonale prøvene i lesing på samisk har vært gjennomført årlig siden 2012, og har dermed begynt å finne sin plass i den samiske skolen og i det samiske samfunnet.

Det er fastsatt et eget Rammeverk for nasjonale prøver i lesing samisk, som tar utgangspunkt i at språk- og opplæringssituasjonen for samiskspråklige elever er annerledes enn for majoritetsspråklige elever i Norge. Rammeverket fastsetter 
at det er elever med samisk som førstespråk som skal gjennomføre de nasjonale prøvene i lesing på samisk. Vi har diskutert begrepene 'opplæringsspråk' og 'førstespråk', og vist at disse ikke er entydige begreper slik opplæringssituasjonen for samiske elever er i dag. Vi har tatt for oss tilgjengelig informasjon om opplæringsspråk og førstespråk i elevpopulasjonen, og utarbeidet statistikk over forholdet mellom disse for de aktuelle årstrinnene. Det er verdt et eget forskningsspørsmål å undersøke den reelle opplæringssituasjonen for samiskspråklige elever. Vi har i dag ikke god nok kjennskap til om elevene virkelig får opplæring på samisk i alle fag, hvilke fag som blir prioritert, og i hvor stor grad lærersituasjonen virker inn på opplæringsspråket. I en slik undersøkelse ville det også være aktuelt å se på læremiddelsituasjonen innen de ulike fagene i sammenheng med opplæringsspråk.

Vi har videre sett på kvalitetssikring i prøveutformingen opp mot utfordringer knyttet til liten elevpopulasjon og flere parallelle språk. Vår måte å kvalitetssikre prøvene på har felles elementer med WHOs prosess for oversettelse og tilpasning av testinstrumenter. Denne prosessen er designet blant annet for å ivareta testinstrumentenes krysskulturelle ekvivalens. Vi ser at det er behov for å videreutvikle metoder for kvalitetssikring av de nasjonale prøvene i lesing på samisk. Det er også behov for å videreutvikle metoder for analyse av resultater og måter å formidle disse resultatene på.

Det er vår oppfatning at de nasjonale prøvene i lesing på samisk er med på å sette samisk språk på dagsorden, både i skolen, blant foreldre og hos skolemyndigheter på ulike nivå. Dette er forhåpentligvis med på å høyne statusen for samisk som språk og befeste samiske språks stilling som fag og som undervisningsspråk. Det er også vår oppfatning at de nasjonale prøvene medvirker til å gi samiske lærere en arena hvor de kan drøfte ulike sider ved leseopplæringen på samisk.

\section{Om forfatterne}

Marit B. Henriksen er seniorrådgiver ved Sámi allaskuvla. Hennes forskningsinteresser omfatter blant annet samisk språk (fonologi og syntaks), dialektforskning, bruken av samisk språk i opplæringen og i akademia, og samisk språk i historiske tekster.

Institusjonstilknytning: Sámi allaskuvla, 9520 Kautokeino.

E-post: marit-breie.henriksen@samiskhs.no

Karen Inga Eira er rådgiver ved Sámi allaskuvla. Hennes forskningsinteresser omfatter blant annet terminologi, lingvistikk, lese- og skriveopplæring. Institusjonstilknytning: Sámi allaskuvla, 9520 Kautokeino.

E-post: karen-inga.eira@samiskhs.no 
Jan Henry Keskitalo er cand.paed.spec., tidligere dosent i samiske skolespørsmål. Han er nå tilknyttet Sámi allaskuvla som honorær veileder. Hans forskningsinteresser omfatter blant annet skoletilbud og læreplaner for urfolk, didaktikk og lærerutdanning, utvikling av læringsressurser, fleksibel læringsplattform i samisk skole, urfolks rettigheter og skoletilbud.

Institusjonstilknytning: Sámi allaskuvla, 9520 Kautokeino.

E-post: Jan-Henry.Keskitalo@samiskhs.no

Kamil Øzerk er professor i pedagogikk ved Universitet i Oslo og Sámi allaskuvla. Hans forskningsinteresser omfatter blant annet tospråklighet, mangfold, læreplanstudier og klasseromsforskning.

Institusjonstilknytning: Institutt for pedagogikk, Universitetet i Oslo, Postboks 1092 Blindern, 0317 Oslo.

E-post: kamil.ozerk@iped.uio.no

\section{Referanser}

Bergsland, K. (1994). Sydsamisk grammatikk. Karasjok: Davvi Girji AS.

Blömeke, S. \& Olsen, R. V. (2018). På vei mot et sammenhengende kvalitetsvurderingssystem. Acta Didactica Norge, 12(4), Art. 1.

Council of Europe (2001). Common European framework of reference for languages: Learning, teaching, assessment. Cambridge: Cambridge University Press. Hentet fra https://rm.coe.int/1680459f97

Eira, K. I. (2018). Elevtall og prøvedeltakelse 2012-2017. Upublisert.

Europakommisjonen (2011). Det felles europeiske rammeverket for språk: Lœring, undervisning, vurdering. Oslo: Utdanningsdirektoratet. Hentet fra https://spraksenteret.osloskolen.no/siteassets/vgs/det-felles-europeiske-rammeverketfor-sprak.pdf

Hawaii State Department of Education (2017). Department pursues expansion of Hawaiian education assessments. Hentet fra: http://www.hawaiipublicschools.org/ConnectWithUs/MediaRoom/PressReleases/Pag es/Hawaiian-education-assessments.aspx

Johansen, K. (2015). Samisk fjernundervisning. I Fagleg analysegruppe for samisk statistikk, Sámi logut muitalit 8. Čielggaduvvon sámi statistihkka 2015. Raporta 1/2015- Samiske tall forteller 8. Kommentert samisk statistikk 2015. Rapport 1/2015 (ss. 58-70). Guovdageaidnu: Sámi allaskuvla. Hentet fra https://www.regjeringen.no/contentassets/c334a9446e6040f8b0c1e56933c0b874/sami ske-tall-forteller-8_norsk.pdf

Kjølaas, J. H. (2005). Tospråklige elevers skolespråk - en undersøkelse av tospråklige elever på mellomtrinnet og deres forståelse av fagtekster. Høgskolen i Tromsø. Hentet fra https://munin.uit.no/bitstream/handle/10037/2288/article.pdf?sequence=1

Kommunal- og moderniseringsdepartementet (2008). Lov om Sametinget og andre samiske rettsforhold (Sameloven). Hentet fra: https://lovdata.no/dokument/NL/lov/1987-06-1256/KAPITTEL_3\#\%C2\%A73-3 
Kunnskapsdepartementet (2018). Lov om grunnskolen og den vidaregåande opplæringa (Oppleringslova). Hentet fra: https://lovdata.no/dokument/NL/lov/1998-07-1761\#KAPITTEL_7

Linkola, I.-A. \& Keskitalo, P. (2015). Sámegiela oinnolašvuohta sámi skuvllas [Sámi language visibility in Sámi schools]. Sámi dieđalaš áigečála (1), 7-28. Hentet fra http://site.uit.no/aigecala/sda-1-2015-linkola-ja-keskitalo/

Nickel, K. P. \& Sammallahti, P. (2011). Nordsamisk grammatikk. Karasjok: Davvi Girji AS.

Nordlandsforskning (2010). Evaluering av LK06 Samisk. Utdanningsdirektoratet. Hentet fra https://www.udir.no/tall-og-forskning/finn-forskning/rapporter/Lareplanverket-forKunnskapskoftet-Samisk-andre-delrapport/

Opetushallitus - Utbildningsstyrelsen (2018). Education system. Hentet fra: https://www.oph.fi/english/education_system

Outakoski, H. (2015). Davvisámegielat čálamáhtu konteaksta [The context of North Sámi literacy]. Sámi dieđalaš áigečála (1), 29-59. Hentet fra: https://site.uit.no/aigecala/sda-12015-hanna-outakoski/

PNPS (2004). Statusrapport for prosjektet Nasjonale prøver i lesing og skriving på nord-, lule- og sørsamisk. Kautokeino: Sámi allaskuvla - Prosjektgruppen for Nasjonale prøver på samisk.

PNPS (2005). Halvårsrapport for prosjektet Nasjonale prøver i lesing og skriving på nord-, lule- og sørsamisk. Kautokeino: Sámi allaskuvla - Prosjektgruppen for Nasjonale prøver på samisk.

PNPS (2006). Halvårsrapport for prosjektet Nasjonale prøver i lesing og skriving på nord-, lule- og sørsamisk, hausten 2006. Kautokeino: Sámi allaskuvla - Prosjektgruppen for Nasjonale prøver på samisk.

Rasmussen, T. (2015). Samisk språk i grunnskolen og videregående opplæring. I Fagleg analysegruppe for samisk statistikk, Sámi logut muitalit 8. Čielggaduvvon sámi statistihkka 2015. Raporta 1/2015 - Samiske tall forteller 8. Kommentert samisk statistikk. Rapport 1/2015 (s. 17-41). Guovdageaidnu: Sámi allaskuvla - Sámi University College.

Rau, C. (2014). Assessing Maori Indigenous Language Learners. I A. J. Kunnan (red.), The Companion to Language Assessment (First edition). Wiley Online Library, John Wiley \& Sons, Inc. doi: https://doi.org/10.1002/9781118411360.wbcla038

Sámediggi - Sametinget (2010). Nordsamisk ortografi. Hentet fra: http://www.giella.no/Filnedlasting.aspx?MId1=1082\&FilId=2595\&back=1\&MId2=1 $\underline{121}$

Sámediggi - Sametinget (2018). Forvaltningsområdet for samiske språk. Hentet fra: https://www.sametinget.no/Tjenester/Spraak\#section-Forvaltningsomraadet-forsamiske-spraak

Sámediggi - Sametinget (2017). Lcreplaner i samisk. Hentet fra: https://www.sametinget.no/Tjenester/Opplaering-og-laeremidler/Laereplaner-isamisk-flere-alternativer\#

Sámi lohkanguovddáš (2008). Notat om rammeverk for nasjonale prøver i lesing på samisk. Kautokeino: Sámi lohkanguovddáš/Senter for samisk i opplæringa, Sámi allaskuvla.

Sámi lohkanguovddáš (2011). Sámi oahpaheaddjefierpmádat, čielggadeapmi [Utredning om samisk lærernettverk]. Guovdageaidnu: Sámi allaskuvla. Hentet

fra: http://samas.no/sites/samas.no/files/utredning_om_samisk_laerernettverk_norsk_oversettelse.pdf

Sammallahti, P. (1998). The Saami Languages - An Introduction. Karasjok: Davvi Girji AS. Skolverket (2018). Nationella prov i sameskolan. Hentet fra: https://www.skolverket.se/undervisning/sameskolan/nationella-prov-i-sameskolan 
Solstad, K. J., Bongo, M., Eriksen, L., Germeten, S., Lyngsnes, K. \& Solstad, M. (2010). Fra plan til praksis. Erfaringer med Kunnskapsløftet Samisk (LK06S). Bodø:

Nordlandsforskning. Hentet fra: https://www.udir.no/tall-og-forskning/finnforskning/rapporter/Lareplanverket-for-Kunnskapskoftet-Samisk-andre-delrapport/

Spiik, N. E. (1989). Lulesamisk grammatik. Jokkmokk: Sameskolstyrelsen.

Todal, J. (2006). Vilkår for utvikling av nasjonale prøver i lesing og skriving på samisk. Norsk Pedagogisk Tidsskrift, 90(5), 404-414. Hentet

fra: https://www.idunn.no/npt/2006/05/vilkar_for_utvikling_av_nasjonale_prover_i_lesing_ogskriving_pa_samisk

Todal, J. (2010). Samisk språk i barnehage og skule. I Fagleg analysegruppe for samisk statistikk, Sámi logut muitalit 3. Čielggaduvvon sámi statistihkka 2010. Raporta 1/2010 Samiske tall forteller 3. Kommentert samisk statistikk 2010. Rapport 1/2010 (s. 154-162). Guovdageaidnu: Sámi allaskuvla - Sámi University College.

Todal, J. (2012). Samisk språk i barnehage og skule 2011/12. I Fagleg analysegruppe for samisk statistikk, Sámi logut muitalit 5. Ċielggaduvvon sámi statistihkka 2012. Raport 1/2012 - Samiske tall forteller 5. Kommentert samisk statistikk. Rapport 1/2012 (s. 104116). Guovdageaidnu: Sámi allaskuvla - Sámi University College.

Todal, J. (2013). Kvantitative endringar i den samiske språksituasjonen i Noreg. I Fagleg analysegruppe for samisk statistikk, Sámi logut muitalit 6. Čielggaduvvon sámi statistihkka 2013. Raporta 1/2013 - Samiske tall forteller 6. Kommentert samisk statistikk 2013. Rapport 1/2013 (s. 15-48). Guovdageaidnu: Sámi allaskuvla - Sámi University College.

UNESCO (2018). UNESCO Atlas of the World's Languages in Danger. Hentet fra: http://www.unesco.org/languages-atlas/index.php?hl=en\&page=atlasmap

Utdanningsdirektoratet (2007). Rammeverk for nasjonale prøver. Oslo, Norge.

Utdanningsdirektoratet (2011). Rammeverk for nasjonale prøver i lesing samisk. Oslo, Norge. Utdanningsdirektoratet GSI. (2018). Grunnskolens informasjonssystem (GSI). Hentet fra: https://gsi.udir.no/

Welsh Government (2018). Learning Wales - Raising standards together. Hentet fra: http://learning.gov.wales/resources/collections/national-reading-and-numeracytests?lang=en

World Health Organization (2018). Process of translation and adaptation of instruments. Hentet fra: http://www.who.int/substance_abuse/research_tools/translation/en/\# 